\title{
Additional Reinforcement in Fixed Fender Structure to Increase Hull Strength
}

\author{
Budianto $^{a^{*}, \text { Fais Hamzah }}{ }^{\mathrm{b}}$, Muhammad Muhadi Eko Prayitno ${ }^{\mathrm{c}}$, Muhammad Shah ${ }^{\mathrm{d}}$, Tri \\ Karyono ${ }^{\mathrm{e}}$ \\ Ship Design and Construction Department, Politeknik Perkapalan Negeri Surabaya, Surabaya, \\ Indonesia \\ a. budianto.structure@gmail.com \\ *corresponding author
}

Keywords: $\quad$ fender; structure; hull; finite element analysis.

Abstract: Types of some fenders on the ship are fixed fenders or inflatable fenders. The most critical part of the hull structure has damaged at fender when it anchoring on the dock or jetty. Some locations of ship's fender structures may experience structural failure such as deformation, buckling, or fracture structures when ship has anchoring on the dock. Especially in fixed fender type, which form as a protector of the hull of a regular ship made of half-pipe material or a box shape. Some reinforcement can be done to increase fixed fender strength by adding and modifying the inside structure such as insert plate, doubling, additional half round plate and addition of flat bar reinforcement structure. Some ways to know the strength of fender structure can be calculated the amount of modulus actual, so it will affect the stresses that occur in structure. The strength of the fixed fender structure in capable the existing load will prevent damage to the hull structure of the ship so that the vessel is safe under operation conditions at the Port. The analysis of stress and shape behaviour of fixed fender structure can be analysed by using finite element analysis (FEA) which is a numerical analysis, structure component dividing into the forms of elements associated with nodal that can move due to effect on the work load. The result of finite element method analysis will give visualization of stress value and the amount of deformation that occurs on the fixed fender structure.

\section{Introduction}

The most crucial structure damage of the ship's hull when it anchors on the dock is a fender. In the ship's structure, the fender is a ship's equipment as a bumper functioned as a reduce absorber on the hull of the ship, which occurs when the vessel will be docked to the port or when the ship is being moored is swayed by waves or affected by sea wave occurring at the port [8]. Fender structure is installed along the sides or shear strake of the vessel to protect or absorb ship reduce which is often encountered during docking positions [11]. Fender materials are generally made of rubber, HDPE, aluminium or steel. While the type of fender type is divided into inflatable fenders and fixed fenders. 
One of the objectives of the ship's fender strength design is to provide ship fenders which is able to of function as protection or sufficient forces with a simple fender construction, easy to manufacture or design, economical, and strong and durable in operational ship [10].

In basic design the shape of the hull, it is expected to reduce the shape of the bend or sharp bends. So in the process of fabrication and assembly block in the placement of fixed fender is much easier in a flat or straight than a ship with many rounded or sharp bending. In the concept of fender design, it is conditioned cheap and simple results that can provide maximum protection on the hull of a ship such as sub-tender and can strengthen the hull construction while operating, whose position has been determined the distance near the water line [4].

A fender structure on a vessel must have a force absorption capacity of impact, low reaction force, smooth exterior surface and no extensive exterior support structure (protruding condition), so it can prevent fender structure caught during operation and reduce maintenance provided [6]. Some locations of the ship's fender structure may experience structural failures such as deformation, buckling, or facture structures when anchoring against the dock. Especially In Fixed Fender type, which serves as a protector of the hull of a regular ship made of half-pipe material or a box shape. Some reinforcement can be done to increase fixed fender strength by adding and modifying the structure inside, inserting plate, doubling and addition of flat bar reinforcement structure.

Some ways to know the strength of fender structure can be calculated the modulus amount, so it can influence the stress that occurs. The strength of the fixed fender structure in withstand the existing load will prevent damage to the hull structure of the ship so that the vessel is safe under operational conditions at the Port or during manoeuvring. With calculation the hydrodynamic method, the approach using the hydrodynamic coefficient depends on the frequency-dependent frequency. The recommended loading behaviour to influence the strength of the impacted fender structure can be accurately calculated including the effect of water depth. It can affect various types of ship hull collisions in longitudinal, lateral, rotational or combination [12].

The design and selection of appropriate fender systems should consider the dynamic interaction between the ship's structure and the harbour or dock condition. The characteristics of the ship's fender system's absorption varies as a function of fender geometry selection, the ship's operating history, special load distribution, local gastric strength and loading frequency [6]. Stresses analysis and shape behaviour of fixed fender structure can be analysed by using finite element method which is numerical analysis, and the structure is divided into the forms of elements associated with nodal that can move because of the effect on the work load. The finite element method consists of a simple approach that uses unknown variables to convert partial differential equations into algebraic equations. The finite element method refers to the three disciplines of engineering science to describe the laws of physics (partial differential equations); Numerical methods for elaboration and solution of algebraic equations; and computing tools to perform the necessary calculations efficiently using a computer [5]. The result of finite element method analysis from computer software will give visualization of stress value and the value of deformation that occurs on the fixed fender structure

\section{Basic of Theory}

\subsection{Definition of Fixed Fender}

Fixed fender is to protect the vessel from damage caused by hull collision against boat to dock or other vessel. fixed fenders create a protective gum bumper that protects the skin, stiffener, girder and ship structure profile. Fixed fenders where the bumper section extends along one side of the ship encompasses a unified strength of sufficient structures to protect the impact of impact from ships or docks. In addition, it also has sufficient character against the friction force with respect to the force that occurs as loading [9]. 


\subsection{Material}

In the selection of ship material requires selecting ship material components that have been certified by the Bureau of Classification [3]. It provides the value of the quality of the built vessel. Based on the material of the ship that is installed must fulfill the standard of Bureau of Classification where using marine used material. The toughness in the strength and corrosion resistance makes the main concern to maintain the quality of ship building.

\subsection{Rules Regulation}

In the development of regulation in ship construction some applicable regulations are such as BKI, $\mathrm{ABS}, \mathrm{GL}, \mathrm{NK}, \mathrm{BV}$ and others. Each classification of the regulation has a critical content in performing standard in accordance with the results of research and design.

\subsection{Meshing}

Meshing is part of the process of finite element method where the structures discrete into the part of elements that are identical to the realistic conditions of the structure object. As for the meshing form, there is a solid or surface depends on doing the finite element simulation [7].

\subsection{Load}

The loading of the ship's structure can be either central or distribution load which is attempt on the surface or nodal on the finite element loading [1]. The amount of loading is determined by the amount of force acting on the ship's structure, in which case the analyzed fender structure is made of steel.

\subsection{Constrain}

Constrain is the placement structure to the object which is analyzed. In this case, it will provide the behavior in accordance with the reality of the structure in which the placement can be a placement of fixed, pinned or rotation.

\subsection{Post processing}

Post processing is part of the analysis using the finite element method with software assisted that displays the results of several conditions in the structure being analyzed. Among other Von Misses stress behavior, normal stress, shear stress, strain, deformation, etc

\section{Methodology}

There are some steps in conducting structural analysis on fender construction. Those steps are as follows:

\subsubsection{Design Modelling}

Design modeling is the process of 3D drawing to fender structure with simulation-structure conditions with real scale, then transformed into export Acis file type.

\subsubsection{Design Study}

This case is to collect the data of previous study in order to obtain valid results. 


\subsubsection{Material type}

This case uses BKI standard material that is Grade A material

\subsubsection{Meshing}

This case uses the type of solid meshing in accordance with 3D model form created.

\subsubsection{Load determination}

Load calculations are performed based on the ship displacement value occurred, which is the force value that can be generated by the vessel.

\subsubsection{Analysis}

In the analysis, it shows the value of stress and deformation on the ship's fender structure, and it looks for the most optimal type of reinforcement structure. Some of the restrictions provided refer to the prevailing regulations such as the flexural stress standard of the fender structure allowable of $188 \mathrm{MPa}$ while the permit shear stress of $90 \mathrm{MPa}$

The following step shows the sequence of workmanship in conducting analysis of the strength of fixed fender structure, they are

- Study literature

- Scantling Calculation

- Design fixed fender

- Additional reinforcement

- Finite element analysis

- Post Processing

- Analysis and Discussion

\section{Analysis and Discussion}

Some forms of analysis and calculation process can be done as follows:

\subsubsection{Design Existing}

The following is fixed fender design on existing ships using steel material. In Figure 1, the sample data used as the main input data of the mid-ship section design of the ships formed. Then the component of fixed fender structure will be in 3D simulation.

In detail existing fixed fender consists of structural components of the fender as follows: half pipe, bracket support and shear strake plate. (as see in Figure 2 - Left).

\subsubsection{Additional Reinforcement}

The fixed fender with reinforcement type A structure consists of half pipe, bracket support, half round plate and shear strake plate as seen Figure 2 - Right. The fixed fender with reinforcement type B structure consists of half pipe, support bracket, doubling plate and shear strake plate as seen in Figure 3 - Left. The fixed fender with reinforcement type $C$ structure consists of half pipe, bracket support, insert plate and shear strake plate as seen in Figure 3 - Right.

\subsubsection{Scantling Calculation}

Displacement at full load condition is the load given by factor strengthen load 1.3 to apply the loading that occurred. The ship displacement value of $=52.54$ tons. Fixed fender is loaded by 
distribution load. It is calculated by rule regulation. Actually load calculation is $35 \mathrm{kN} / \mathrm{cm}^{2}$ and it distributes fixed fender area.

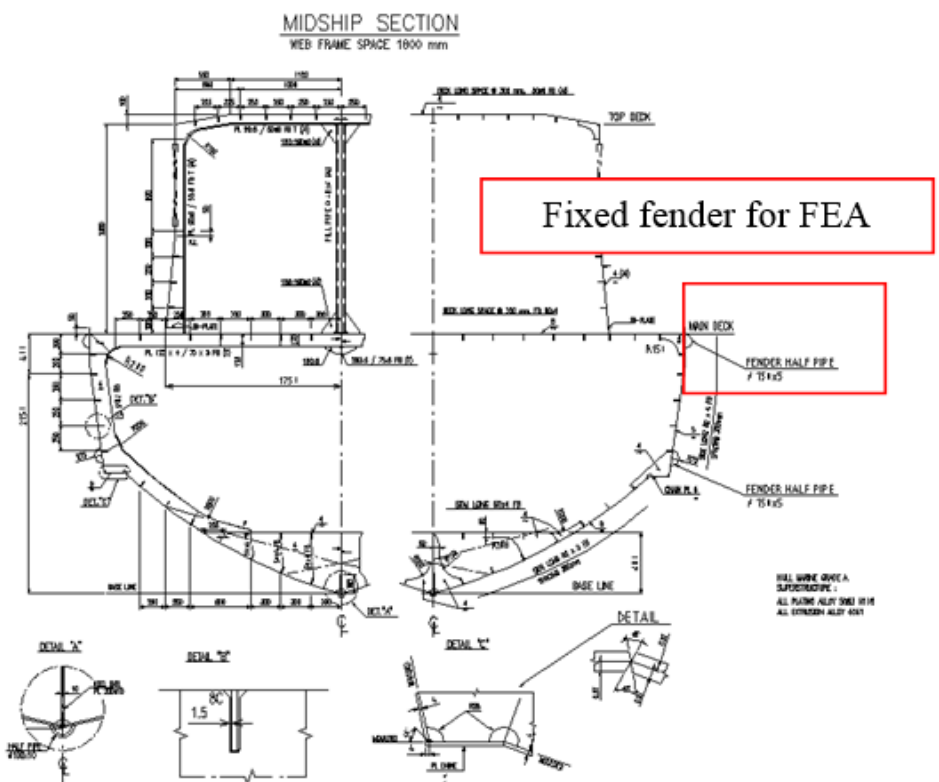

Figure 1. Midship Section

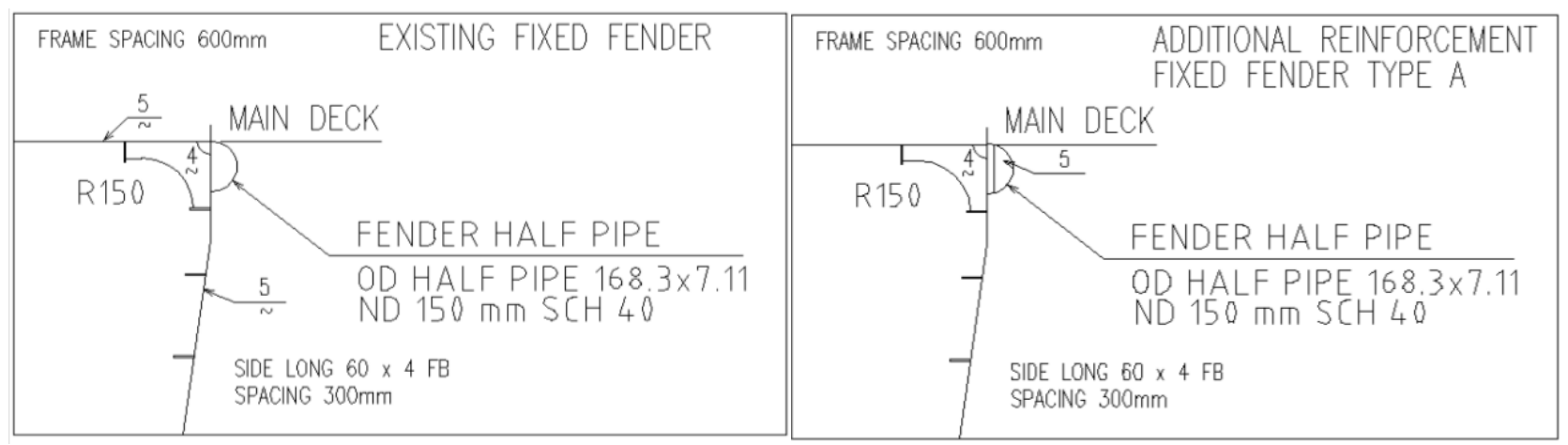

Figure 2. Existing Fixed Fender (Left); Design of additional reinforcement type A (Right)

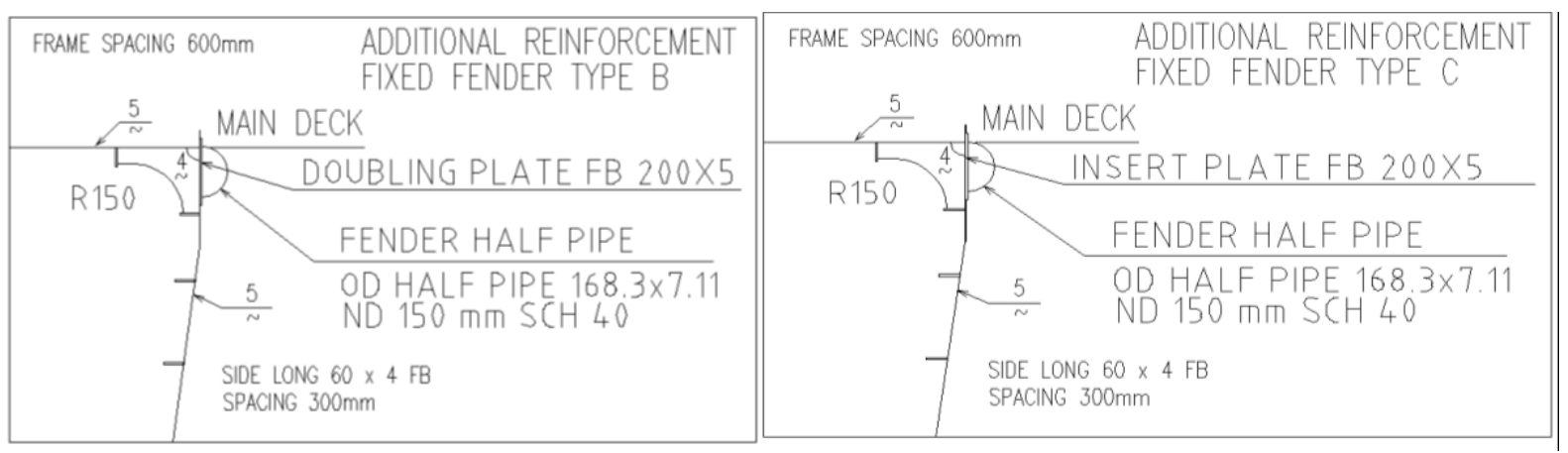

Figure 3. Design of additional reinforcement type B (Left); Fig. 5. Design of additional reinforcement type $\mathrm{C}$ (Right) 


\subsubsection{Finite Element Result}

The following shows the value of VonMiss stress on the existing fixed fender with a value of 162.84 MPa stress approaching the allowable voltage value of $188 \mathrm{MPa}$ as seen in Figure 4. Figure 5 shown VonMises stress value on fixed fender with reinforcement type A with a stress value of 150.22 MPa. Figure 6 shown VonMises stress value on fixed fender with reinforcement type B with a stress value of $137.58 \mathrm{MPa}$

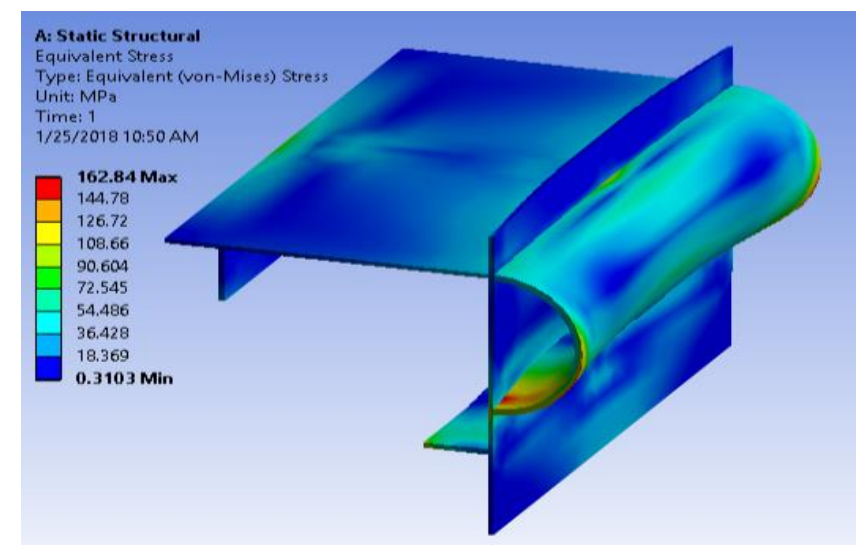

Figure 4. FE Result for Existing Fixed Fender

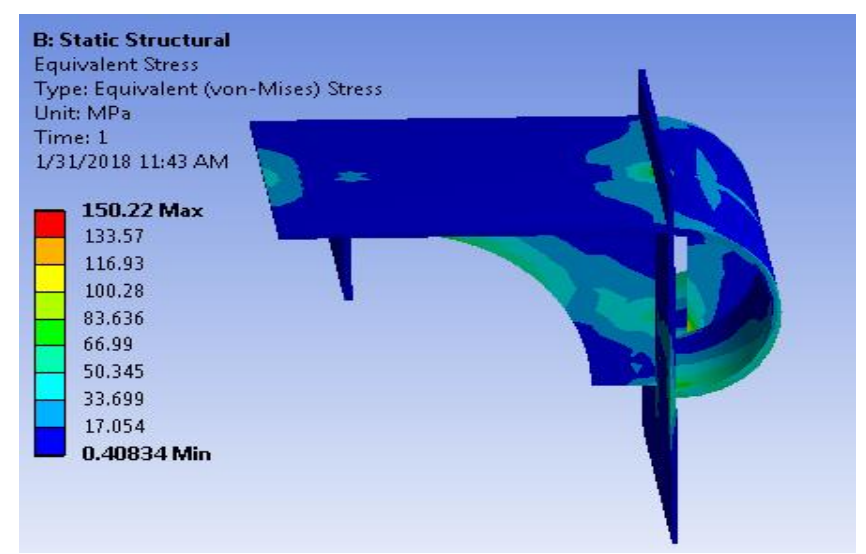

Figure 5. FE Result for fixed fender type A

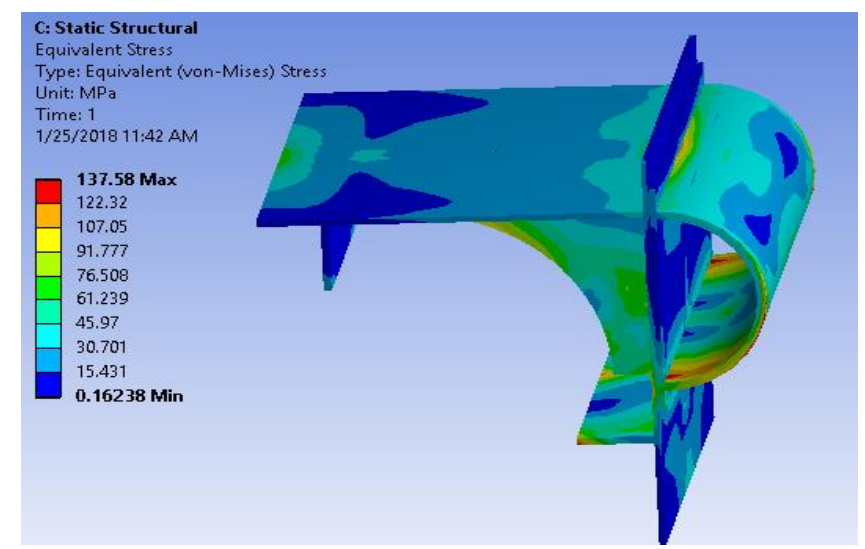

Figure 6. FE Result for fixed fender type B 
Figure 7 shown VonMises stress value on fixed fender with reinforcement type $\mathrm{C}$ with a stress value of $114.91 \mathrm{MPa}$.

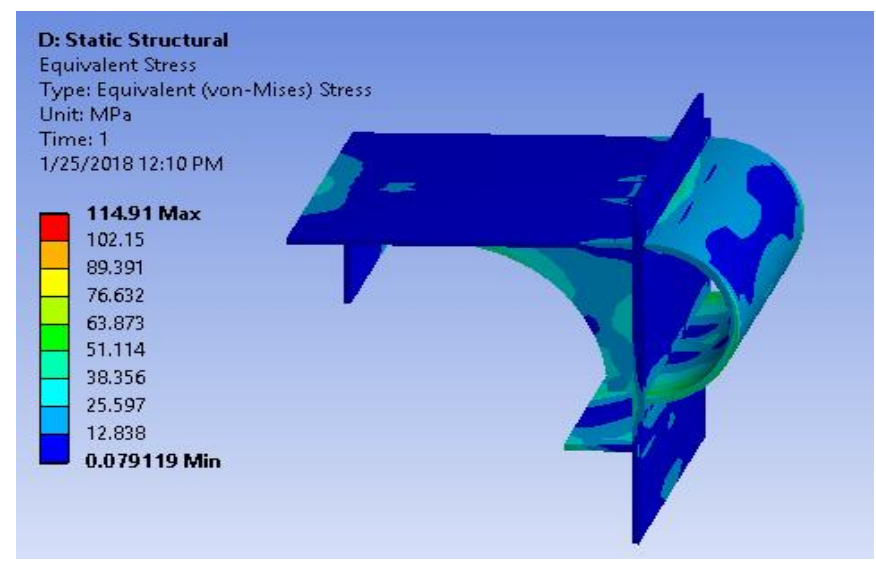

Figure 7. FE Result for fixed fender type C

\subsubsection{Stresses and Deformation}

From the results of analysis on FE in Table I which is done by adding reinforcement will strengthen the structure. It is because the number of modulus given increases and reduces the voltage that occurs. The most effective form of reinforcement is type $\mathrm{C}$ reinforcement. Conclusion with additional reinforcement in fixed fender structure to increase hull strength where it can reduce actually stresses.

Table 1. Structure Behaviour

\begin{tabular}{|l|c|c|c|}
\hline \multirow{2}{*}{\multicolumn{1}{|c|}{ Table Head }} & \multicolumn{3}{|c|}{ Fixed fender } \\
\cline { 2 - 4 } & $\begin{array}{c}\text { Stress } \\
\mathbf{N} / \mathbf{m m}^{\mathbf{2}}\end{array}$ & $\begin{array}{c}\text { Shear } \\
\mathbf{N} / \mathbf{m m}^{\mathbf{2}}\end{array}$ & $\begin{array}{c}\text { Deformation } \\
(\mathbf{m m})\end{array}$ \\
\hline Existing & 162.84 & 83.21 & 6.58 \\
\hline $\begin{array}{l}\text { Additional reinforcement } \\
\text { Type A }\end{array}$ & 150.22 & 60.82 & 2.36 \\
\hline $\begin{array}{l}\text { Additional reinforcement } \\
\text { Type B }\end{array}$ & 137.58 & 58.78 & 1.34 \\
\hline $\begin{array}{l}\text { Additional reinforcement } \\
\text { Type C }\end{array}$ & 114.91 & 52.36 & 0.56 \\
\hline
\end{tabular}

\section{Acknowledgements}

Thanks to lectures and researchers in PPNS for supporting and sharing knowledge in Campus.

\section{References}

[1] Budianto, M. T Wahyudi, U Dinata, Ruddianto and M.M. Eko P. "Strength Analysis on Ship Ladder Using Finite Element Method." Journal of Physics: Conference Series. Vol. 953. No. 1. IOP Publishing, 2018.

[2] Biro Klasifikasi Indonesia. "Rules For The Classification and Construction Of Seagoing Steel Ships”, 2016.

[3] Brown Jr, Louis S. "Marine fender." U.S. Patent No. 4,351,257. 28 Sep. 1982.

[4] Darling, James P. "Ship fender." U.S. Patent No. 3,125,979. 24 Mar. 1964.

[5] Dhatt, Gouri, Emmanuel LefranÃ, and Gilbert Touzot. Finite element method. John Wiley \& Sons, 2012. 
[6] Jiang, Chen-wen, and Richard C. Janava. An Analytical Technique for Ship-Fender Interaction. No. GA-31-115002. GIANNOTTI AND ASSOCIATES INC ANNAPOLIS MD, 1983.

[7] Knight, Katrina, Pamela Moalli, and Steven D. Abramowitch. "Preventing Mesh Pore Collapse by Designing Mesh Pores with Auxetic Geometries: A Comprehensive Evaluation via Computational Modeling." Journal of biomechanical engineering (2018).

[8] Lebedev, Dmitrii, and Gennadiy Kryzhevich. "Development of a New Advanced Fender Design With High ShockAbsorbing and Damping Properties." ASME 2017 36th International Conference on Ocean, Offshore and Arctic Engineering. American Society of Mechanical Engineers, 2017

[9] Stevens, William E. "Marine fender for pilings of marine structures." U.S. Patent No. 5,018,471. 28 May 1991.

[10] Ulgen, Mehmet Nevres. "Fender assembly untuk kapal." Paten AS No. 9.038.556. 26 Mei 2015.

[11] Urquhart, William R., and Elov F. Maas. "Ship fender." U.S. Patent No. 2,117,121. 10 May 1938. 